\title{
PENDEKATAN SOSIOLOGI DALAM KAJIAN PENDIDIKAN ISLAM
}

\author{
Daimah ${ }^{1}$, Setyo Pambudi ${ }^{2}$ \\ Program Studi Pendidikan Agama Islam, UIN Sunan Kalijaga \\ email : sholihahdaimah@gmail.com HP 085828539843, setyopambudi29@gmail.com \\ HP 085741332212
}

\begin{abstract}
This article analyses the Sociology of Education that refers to the application of sociological knowledge, thinking techniques, and data collection in educational investigations. The sociology of education studies the process of education as social interaction, school as a social group, and as a social institution. Sociological analysis models of education include 4 types of analysis, (1) analysis of functional structural models with characters Emile Durkeim and Talcott Parsons, (2) analysis of conflict models with characters S. Bowles and H. Gintis and Louis Althuser, (3) analysis the critical sociology model with its characters Paulo Freire and Ivan Illich and (4) Analysis of the English and US versions of Micro-level Education.
\end{abstract}

Keywords: Sociology Theory, Islamic Education, Sociological analysis models, the process of education

\begin{abstract}
ABSTRAK
Sosiologi Pendidikan mengacu pada penerapan pengetahuan sosiologi, teknik berfikir, dan pengumpulan data dalam penyelidikan pendidikan. Dengan demikian sosiologi pendidikan mempelajari tentang proses pendidikan sebagai interaksi sosial, sekolah sebagai kelompok sosial, serta sebagai lembaga sosial. Model-model analisis sosiologi tentang pendidikan meliputi 4 macam analisis, (1) analisis model struktural fungsional dengan tokohnya Emile Durkeim dan Talcott Parsons, (2) analisis model konflik dengan tokohnya S. Bowles dan H. Gintis dan Louis Althuser, (3) analisis model sosiologi kritis dengan tokohnya Paulo Freire dan Ivan Illich dan (4) Analisis Pendidikan Level Mikro versi Inggris dan Amerika Serikat.
\end{abstract}

Kata Kunci : Teori Sosiologi, Pendidikan Islam 


\section{PENDAHULUAN}

Dinamika perubahan di dalam masyarakat menunjukkan bahwa masyarakat sangat cepat, maju dan memperlihatkan adanya gejala desintegratif. Perubahan sosial itu meliputi berbagai bidang kehidupan, dan merupakan masalah bagi semua institusi soaial, seperti: industri, agama, perekonomian, pemerintahan, keluarga, perkumpulan-perkumpulan dan pendidikan. Masalah sosial dalam masyarakat itu juga dirasakan oleh dunia pendidikan. Jadi yang melatarbelakangi timbulnya sosiologi pendidikan adalah perubahan sosial yang dialami oleh masyarakat yang begitu cepat.

Menurut Gunawan (2010) Perubahan sosial itu menimbulkan cultural lag. Cultural lag ini merupakan sumber masalah-masalah sosial dalam masyarakat dan masalah-masalah itu dialami oleh dunia pendidikan. Lembaga-lembaga pendidikan tidak mampu mengatasinya. Oleh karena itu, kegiatan manusia sebagai mahluk sosial itu akan menimbulkan berbagai ilmu pengetahuan sendiri. Termasuk ialah kegiatan manusia untuk mendidik generasi-generasi mudanya, dengan memberikan, menundakan mewariskan kebudayaannya kepada anak cucunya. Di dalam karya mendidik inilah manusia berusaha untuk mengetahui bagaimanakah proses pendidikan itu dilihat dari segi sosialnya, ditinjau dari konstelasi sosial, dimana terjalin karya mendidik itu. Maka disini timbullah suatu cabang ilmu pengetahuan ialah sosiologi pendidikan. Dewasa ini ilmu pengetahuan telah berkembang pesat, terutama dalam bidang teknologi modern, Ilmu sosiologipun tidak mau ketinggalan. Salah satu diantaranya adalah Sosiologi Pendidikan. Ilmu ini masih sangat muda dan masih memerlukan pembinaan, terutama dilingkungan akademis.

\section{A. Pengertian Sosiologi Pendidikan}

Sosiologi berasal dari dua kata, sosiologi dan pendidikan. Pada awalnya sosiologi berkembang sesuai dengan obyek dan tujuanya sendiri, demikian pula pendidian. Dengan adanya perkembangan masyarakat yang begitu cepat dalam segala aspek kehidupan, memerlukan pengetahuan sesuai dengan kebutuhan. Sosiologi tidak dapat memenuhi kehidupan masyarakat, demikian pula kalau hanya pendidikan saja. Perkembangan masyarakat yang sangat kompleks memerlukan ilmu pengetahuan yang sangat kompleks pula. Salah satunya adalah sosiologi pendidikan.

Para ahli telah memberikan pengertianya, terutama dalam mendefinisikan sosiologi pendidikan, diantaranya:

1. Charles A. Ellwood. Sosiologi pendidikan adalah ilmu pengetahuan yang mempelajari tentang maksud hubungan-hubungan antara semua pokok masalah antara proses pendidikan dan proses sosial. 
2. FG. Robbin dan Brown. Sosiologi pendidikan adalah ilmu yang membicarakan dan menjelaskan hubungan-hubungan sosial yang mempengaruhi individu untuk mendapatkan serta mengorganisasikan pengalaman. Sosiologi pendidikan mempelajari kelakuan sosial serta prinsip-prinsip mengontrolnya.

3. Menurut. S. Nasution, sosiologi pendidikan adalah ilmu yang berusaha untuk mengetahui cara-cara mengendalikan proses pendidikan untuk mengembangkan kepribadian individu agar lebih baik.

Penelitian oleh lee dalam Nasution (1994), menunjukan bahwa diantara mata kuliah sosiologi pendidikan yang diberikan diberbagai perguruan tinggi hanya sedikit persamaannya. Demikian pula halnya dengan buku-buku sosiologi yang digunakan dalam berbagai lembaga pendidikan.

\section{B. Sejarah Perkembangan Sosiologi Pendidikan}

Di dalam buku Abu Ahmadi dan St. Vembrianto yang berjudul Sosiologi Pendidikan dinarasikan mengenai perjalanan ilmu sosiologi pendidikan sebagai berikut: perkembangan ilmu ini dimulai dari Lester F. ward yang dianggap sebagai penerus gagasan timbulnya study baru ini. Ward hadir dengan idenya mengenai evolusi sosial. Juga menekankan peranan pendidikan sosial yang realistis dalam memimpin perencanaan kehidupan pemerintahan. Sedangkan, pelopor sosiologi pendidikan dalam arti formal ialah John Dewey yang menerbitkan buku School and Society tahun 1889. Dalam buku tersebut, dijelaskan pendapatnya mengenai sekolah sebagai lembaga sosial. Pada waktu itu beberapa ahli ilmu pendidikan dan sosiologi menekankan pentingnya peranan sosiologi bagi pendidikan. Tokoh-tokoh, seperti A.W. Small, E.A. Kirkpatrick, C.A.Ellwood, Alvin Good, dan S.T. Dutton mempersoalkan pentingnya mempersoalkan pentingnya menghubungkan pendidikan dengan pengalaman anak dalam keluarga dan masyarakat. Kemudian, buku lainya yang terkenal adalah Democracy and Educational di tahun 1916, lebih jauh mendorong timbulnya sosiologi pendidikan. Selanjutnya, pada tahun 1920, F.R. Clow Dawwid Snedden, Ross Finney, C.C. Peters, C. L. Robbins, E.R.. Grovers, dan lain-lain meneruskan jalan fikiran tersebut diatas dan menekankan pentingnya nilai sosial pendidikan.

Sosiologi pendidikan pertamakali dikuliahkan oleh Henry Suzzalo tahun 1910 di Teacher College, Universitas Columbia. Akan tetapi, baru saja tahun 1917 terbit textbook sosiologi pendidikan yang pertama kali karya Walter R. Smith dengan judul Introduction to Educational Sociology. Pada tahun 1916, di Universitas New York dan Columbia didirikan jurusan Sosiologi 
Pendidikan dibentuk pada konggres himpunan sosiologi Amerika dalam tahun 1923. Sejak tahun itu diterbitkan buku tahunan sosiologi pendidikan. Pada tahun 1928, diterbitkan The Journal of Educational Sociology dibawah pimpinan E. George Payne. Majalah Social Education mulai diterbitkan tahun 1936. Sejak tahun 1940, dalam Review Education Reserch dimuat pada artikelartikel yang berhubungan dengan sosiologi pendidikan.Sementara, di Indonesia, pada tahun 1967, sosiologi pendidikan diberikan pertama kali diajarkan di IKIP Negeri Yogyakarta Jurusan Diktaktik Kurikulum.

\section{Ruang Lingkup Sosiologi Pendidikan}

Sosiologi pendidikan mengacu pada penerapan pengetahuan sosiologi, teknik berfikir, dan pengumpulan data dalam penyelidikan pendidikan. Dengan demikian sosiologi pendidikan mempelajari tentang proses pendidikan sebagai interaksi sosial, sekolah sebagai kelompok sosial, serta sebagai lembaga sosial. Sosiologi pendidikan mempunyai manfaat yang besar bagi para pendidik. Sumbangan sosiologi pendidikan adalah memberikan hasil analisis dalam hubungan antar manusia di dalam sekolah dan struktur masyarakat di mana sekolah itu berada.

Dengan sosiologi pendidikan, dapat dipelajari pola-pola interaksi dalam sistem pendidikan. Namun demikian, sosiologi pendidikan tidak saja mempelajari tentang pendidikan sebagai obyeknya, namun juga tujuan pendidikan dan bahan kurikulum. Sosiologi pendidikan merupakan analisis ilmiah tentang proses sosial dan pola sosial yang terdapat dalam sebuah sistem pendidikan. Hal ini didasarkan kepada kenyataan bahwa sistem pendidikan merupakan serangkaian kombinasi tindakan sosial. Beberapa kajian yang masuk dalam sosiologi pendidikan adalah melihat pola hubungan antara sistem pendidikan dengan proses sosial dan perubahan yang ada, analisa terhadap struktur sosial yang ada di dalam sistem pendidikan, pola hubungan antara struktur kekuasaan yang ada di dalam masyarakat dengan sistem pendidikan, serta bagaimana pola stratifikasi yang berlaku dalam masyarakat dan kaitanya dengan sistem pendidikan. Masih banyak kajian yang dikembangkan dalam sosiologi pendidikan.

Menurut Bambang dan Husni (2012)Teori dan konsep metode penelitian sosiologi menawarkan seperangkat alat untuk memikirkan pendidikan. Sosiologi tidak melihat perilaku manusia sebagai kegiatan manusia, tetapi mencari keteraturan dan kesamaan dalam perilaku yang mengacu pada konteks kelompok. Dengan demikian suatu cara yang shahih untuk menjelaskan kegiatan manusia adalah menganggap kegiatan itu sebagai hasil dari pengalaman manusia. 


\section{Model-model Analisis Sosiologi dalam Mengkaji Pendidikan}

Adiwikarta (2016) menjelaskan bahwa sosiologi pendidikan adalah analisis sosiologi tentang praktis pendidikan, atau penerapan teori-teori sosiologi dalam menganalisis praktis pendidikan. Pernyataan tersebut menjelaskan bahwa sosiologi pendidikan menuntut pengetahuan yang cukup kuat tentang teori-teori sosiologi. Penguasaan teori-teori sosiologi merupakan satu persyaratan yang tidak dapat ditawarkan lagi bagi analisis sosiologi pendidikan. Tanpa teori sosiologi, analisis sosiologi tidak akan terjadi dan sosiologi pendidikan hanya akan merupaka deskripsi datau atau laporan gambaran apa adanaya tentang pendidikan itu. Oleh karena itu, untuk memenuhi tuntutan tersebut akan disajikan model-model analisis pendidikan dengan menggunakan berbagai teori sosiologi yang didahului dengan keterangan mengenai karakteristik dasar sosiologi.

1. Analisis Model Struktural Fungsional

Teori struktural disebut juga teori konsesus (consesus), teori integrasi, atau teori keseimbangan (equilibrium). Teori ini berangkat dari asumsi bahwa kehidupan masyarakat merupakan sebuah sistem besar yang terdiri atas sejumlah subsistem yang saling pengaruhi dan saling tergantung serta terintegrasi satu sama lain dalam membuat masyarakat itu berfungsi. Hubungan saling pengaruhi itu bukan hanya antar subsistem malainkan juga antara subsistem-subsistem kehidupan dengan lingkungan. Artinya, perubahan keadaan lingkungan berpengaruh terhadap berbagai aspek kehidupan, dan sebaliknya. Oleh karena itu model analisis ini biasa disebut model analisis sistem. Kesepakatan atau konsesus akan nilai dianatara warga suatu masyarakat membuat masyarakat terintegrasi, bersatu, dan stabil. Kalaupun terjadi perubahan, perubahan itu berlangsung perlahan-lahan dalam keadaan seimbang tanpa guncangan, sehingga terbentuk keseimbangan yang dinamis.

Para ahli sosiologi Pendidikan pendukung teori ini memusatkan perhatian akan fungsi pendidikan dalam kehidupan. Pertanyaan pokok yang mereka ajukan adalah apa fungsi pendidikan dalam masyarakat. Analisisnya terfokus pada level makro dari kehidupan. Berikut akan dikemukakan beberapa tokoh utama teori ini beserta pokok-pokok pemikirannya.

a. Emile Durkheim (1858 - 1917)

Analisis pendidikan Durkheim memberikan penekanan pada pembahasan tahap makro dengan pengkhususan peran pendidikan dalam proses sosialisasi, seleksi, distribusi, pelestarian dan perubahan budaya, dan integrasi sosial, serta memelihara tertib sosial dan keseimbangan sosial. 
Pendidikan didefinisikan sebagai proses mempengaruhi yang dilakukan generasi orang dewasa kepeda mereka yang belum siap untuk melakukan fungsi-fungsi sosial. Sasarannya adalah melahirkan dan mengembangkan sejumlah kondisi fisik, intelek dan watak, sesuai tuntutan masyarakat politik (bangsa) secara keseluruhan dan tuntutan lingkungan khusus tempat mereka akan hidup dan berada.

b. Talcott Parsons $(1920-1979)$

Seperti halnya Durkheim, Parsons melihat pendidikan sebagai pemegang fungsi sosialisasi dan seleksi. Akan tetapi pada kedua fungsi itu Parsosns memberikan tekanan pada pentingnya fungsi pertama, yaitu sosialisasi. Sosialisasi meliputi segala aspek kehidupan : nilai, kognisi, maupun motorik. Diantara ketiga aspek itu ia mengutamakan sosialisasi nilai, karena konsesus akan nilai merupakan faktor yang disyaratkan bagi timbuldan terpeliharanya integrasi sosial. Melalui sosialisasi, nilai-nilai budaya yang dimiliki masyarakat diubah menjadi nilai yang dihayati atau diinternalisasikan oleh setiap warga masyarakat secara individual.

Sudarja mengemukakan pendidikan adalah proses sosialisasi yang dalam diri individu memungkinkan berkembangnya kecakapan-kecakapan dan rasa tanggung jawab (capacity and commitment) yang semuanya diperlukan dalam melaksanakan peran-peran sosial. Oleh karena itu dapat disimpilkan bahwa analisis pendidikan Parsons tidak hanya pada level makro akan tetapi juga memperhatikan level kelembagaan (meso). Ada dampak dalam proses sosialisasi yang berbeda pada orang yang berbeda, karena pelaku sosialisasi memiliki kapasitas yang berbeda.

\section{Analisis Model Konflik}

Analisis konflik bertolak dari teori konflik Karl Marx (1818 - 1883), sosiolog Jerman. Menurut Karl Marx, dalam masyarakat kapitalis terdapat dua kategori manusia, yaitu kaum borjuis dan proletar. Kaum borjuis adalah kaum minoritas yang menguasai faktor produksi, sedangkan kaum proletar merupakan mayoritas warga masyarakat hanya memiliki tenaga dan keterampilan untuk dijual kepada kaum burjois. Dengan demikian, penganut teori konflik melihat bahwa pada setiap masyarakat ada sekelompok kecil manusia yang mendominasi kelompok mayoritas. Bertolak dari pemikiran Karl Marx tersebut, para pemikir pendidikan melakukan pengkajian pada level makro mengenai peran pendidikan dalam membuat sistem kemasyarakatan bisa bertahan. Mereka melihat pendidikan dari kacamata yang berbeda dengan kaum struktural fungsional, dengan asumsi pada sistem kemasyarakatan yang berbeda berlangsung sistem pendidikan yang berlainan. 
Hal yang menjadi benang merah dalam analisis model konflik adalah bahwa pendidikan merupakan sarana kaum dominan (penguasa) untuk menanamkan nilai-nilai yang dianut oleh mereka kepeda generasi muda, dalam rangka mempertahankan struktur sosial yang ada atau dalam rangka mempertahankan status quo untuk mengekalkan dominasi mereka. Oleh karena itu dalam pandangan kaum teori konflik, sosialisasi didefinisikan sebagai proses pewarisan nilai-nilai kaum penguasa dari suatu generasi ke generasi berikutnya dalam rangka mempertahankan dominasi, yaitu agar anak mudanya mengikuti nilai-nilai yang dimiliki dan dianggap baik oleh generasi sebelumnya.

a. S. Bowles dan H. Gintis

Bowles dan Gintis melihat bahwa USA menganut sistem ekonomi kapitalis totaliter yang ditandai dengan dominasi kaum minoritas (penguasa dan menejer) terhadap mayoritas (kaum buruh dan pekerja). Pada masa tersebut, pendidikan dilakukan dengan dua macam strategi, pertama, menanamkan kepercayaan bahwa keberhasilan dibidang ekonomi amat tergantung pada pemilikan kemampuan dan keterampilan atau pendidikan yang baik. Kedua, mempersiapkan generasi muda dengan pembelakalan pengetahuan dan keterampilan untuk bisa mengisi posisiposisi yang tersedia dalam masyarakat sesuai dengan kepentingan kaum kapitalis. Melalui pendidikan, mereka menciptakan kaum elit muda yang akan meneruskan dominasi ekonomi dalam masyarakat. Pendidikan merupakan alat reproduksi langsung masyarakat kapitalis untuk memelihara dan mempertahankan status quo, bukan sarana perubahan sosial untuk menangani kesenjangan kesejahteraan.

b. Louis Althuser

Sejalan dengan analisis Bowles dan Gintis, yaitu bahwa pendidikan pada masyarakat kapitalis berperan mempertahankan dan memperkuat hubungan produksi kapitalis, memeprkuat kaum dominan (minoritas) dalam mempertahankan dominasi dan status quo. Bedanya adalah bahwa Althuser memandang pendidikan pada masyarkat kapitalis sebagai perlengkapan penguasa (negara) dalam rangka menanamkan dominasi dan mempertahankan status quo, sebagai perlengkapan yang tidak bercorak memaksa.

Dalam menanamkan dan mempertahankan status quo itu negara/masyarakat kapitalis memiliki dua kategori peralatan dan perlengakan, yaitu yang bersifat menekan atau memaksan dan yang membentuk atau mengubah sifat mental. Kategori yang menekan atau memaksa (refresif) meliputi perundang-undangan, polisis, angkatan perang, perangkat pemerintahan dan administrasi. Fungsi dasar 
kategori ini adalah bertindak atas nama penguasa dalam perjuangan kelas mereka dengan menggunakan tekanan dan paksaan. Sementara itu kategori yang kedua berperan membentuk atau mengubah sikap mental masyarakat tanpa tekanan dan paksaan. Tidak ada sanksi dan hukuman terhadap penyimpangan-penyimpangan yang dilakukan. Pelengkapan negara ini meliputi pendidikan yang disampaiakn melalui sekolah, agama, keluarga, politik, budaya, sastra, organisasi perusahaan dan lain-lain.

\section{Analisis Model Sosiologi Kritis}

Model analisis Sosiologi kritis mengacu kepada teori sosiologi kritis yang berkembang di Frankfurt, Jerman mulai dekade 1920-an. Model analisis pendidikan yang berdasar pada teori ini mendorong emansipasi kaum lemah yang tersisihkan dalam masyarakat. Hal yang menjadi fokus perhatiannya adalah memperbaiki peristiwa-peristiwa aktual dalam pendidikan, baik pada level makro maupun mikro yang dinilai kurang memperhatikan kaum lemah yang memerlukan bantuan.

Pada level mikro, dalam lingkungan unit pendidikan, analisis sosiologi kritis melihat bahwa para pelajar berada pada posisi lemah, pasif, dibentuk, terkungkung dan harus tunduk kepada kurikulum dan guru yang dipandang sebagai wakil negara, bangsa dan orang dewasa di sekolah. Oleh karenanya, untuk keluar dari situasi ini kurikulum dan pelaksanaannya diharuskan memfokuskan perhatian kepada kepentingan siswa (student oriented). Model pembelajaran harus mengembangkan kreativitas dan daya kritis peserta didik. Definisi pendidikanpun berubah menjadi berorientasi pada peserta didik sebagai berikut,

“.........usaha sadar untuk mewujudkan suasana belajar agar peserta didik secara aktif mengembangkan potensi dirinya untuk memiliki kekuatan spiritual, keagamaan, pengendalian diri, kepribadian, kecerdasan, akhlak mulia, serta ketrampilan yang diperlukan dirinya, masyarakat, bangsan dan negara”,

a. Paulo Freire

Dalam Abdullah (2013) Paulo Freire melukiskan bahwa dalam pendidikan tradisional, guru memainkan peran sangat dominan dalam interaksinya dengan pelajar. Dalam sisitem pendidikan tradisional itu proses pembelajaran digambarkan sebagai sistem bank yang didalamnya guru diibaratkan sebagai seseorang yang menuang air kepada wadah/tempayang kosong yang pasif dan tidak bereaksi apa-apa. Pelajar tidak punya kesempatan untuk berdialog dengan guru. Menurutnya, sistem 
pendidikan yang demikian akan menghasilkan pelajar dan lulusan yang menganut Budaya Bisu (culture of silent). Oleh karenanya untuk memperbaiki keadaan ini pendidikan harus mampu mengembangkan 'critical consciousness' (kesadaran kritis, kemampuan untuk bersikap dan berbuat kritis kepada keadaan) dikalangan pelajaran melalui pendekatan dialogis.

b. Ivan Illich

Dalam bukunya 'Deshooling Society' ia mengemukakan bahwa selama ini sekolah merupakan tempat anak-anak ditekan dan dipaksa untuk mempelajari hal-hal yang tidak mereka sukai atau kehendaki. Belajar yang baik berlangsung dalam suasana bebas yang memungkinan pelajaran memilih sendiri pelajaran yang disukainya. Illich selanjutnya menyarankan agar sisitem persekolahan itu dibubarkan saja karena tidak efektif. Anak-anak lebih banyak belajar sendiri pengetahuan diluar sekolah, seperti membaca buku, koran, mendengarkan radio, nonton film, dan televisi melalui pergaulan dan lain-lain dibanding sekolah.

Karya Paulo Freire dan Ivan Illich mendapat banyak perhatian dari para pemikir dan pengamat pendidikan yang belakangan ini membahasnya dalam berbagai buku. Demikianlah, kehidupan di sekolah dan di dalam kelas harus difokuskan pada kepentingan, minat dan kemampuan belajar siswa yang selama ini terabaikan. Sekolah dan kelas diharapkan menjadi lingkungan belajar yang menyenangkan dan menguntungkan bagi pihak yang paling memerlukan dalam rangka mewujudkan potensi yang dimilikinya semaksimal mungkin.

\section{Analisis Pendidikan Level Mikro}

Model analisis level mikro berkembang di Inggris dan di Amerika Serikat dalam waktu yang tidak berjauhan, sekitar pertengahan abad yang lalu. Antara keduanya terdapat perbedaan dan persamaan karakteristik sebagai berikut.

a. Model Analisis Level Mikro di Inggris

Pada awal dekade 1960-an di Inggris berkembang model analisis yang mendapat julukan 'New Sociology of Education'. Model analsis ini bermula dari ketidakpuasan masyarakat Inggris akan kebijakan dan pelaksanaan pendidikan di sekolah beserta hasilnya. Pendidikan persekolahan dianggap gagal dalam mencapai tujuannya yaitu membentuk manusia paripurna, memanusiakan manusia.

Hal yang menjadi tujuan utama New Sociology of Education adalah perbaikan sistem pendidikan agar dihasilkan manusia seutuhnya. Arah perbaikan yang dituju 
sama dengan model yang dikemukakan Sosiologi Kritis yaitu selain dari peningkatan kualitas pendidikan, ia juga tidak boleh bernuansa politik rasialis dan seagreatif, malainkan harus merata untuk setiap lapisan dan golongan masyarakat, serta harus berpihak kepada kaum lemah yang paling memerlukan pertolongan. Perbedaannya dengan model Sosiologi Kritis adalah bahwa 'New Sociology of Education' melakukan analisisnya pada level mikro, mengkaji pelaksanaan pembelajaran di sekolah, di dalam kelas, meliputi isi pendidikan (kurikulum), metode pembelajaran, perlakuan guru terhadap peserta didik, dan lain-lain yang berkeitan dengan pembelajaran disekolah/kelas.

b. Model Analisis Mikro di Amerika Serikat

Hampir bersamaan dengan perkembangan 'New Sociology of Education' di Inggris, di Amerika Serikat berkembang model analisis mikro yang dilandasi teori Interaksi Simbolik dan Teori Fenomenologi dalam sosiologi. Teori interaksi simbolik memiliki sejumlah karakteristik pokok dan asumi-asumsi antara lain: untuk memperoleh pemahaman yang baik tentang pendidikan harus dilakukan pengkajian terhadap kegiatan sehari-hari di sekolah, di dalam kelas, terhadap orang-orang yang berinteraksi, saling berhubungan dan saling berpengaruh satu sama lainnya, khususnya antara murid dengan guru dan anatar murid-murid satu sama lain. Dalam interaksi berlangsung proses komunikasi dengan menggunakan simbol-simbol. Keberhasilan interaksi atau komunikasi memerlukan dukungan media yang relevan dan situasi yang kondusif. Oleh karena itu, ketersediaan dan penggunaan media pembelajaran yang relevan serta situasi yang kondusif bagi pelaksanaan pendidikan merupakan sesuatu hal yang mutlak diperlukan.

Teori fenomenologi merupakan suatu aliran filsafat yang berpendapat bahwa semua pengetahuan yang kita miliki diperoleh melalui alat indera (penglihatan, pendengaran, penciuman, perasaan, dan perabaan); yang lain dianggap spekulasi. Jadi menurut pemikiran penganut kedua teori tersebut, analisis pendidikan yang didasari oleh tiga hal sebagai berikut : (1) Informasi lapangan diperoleh dengan pendekatan fenomenologi, (2) Objek kajian berupa isi dari pendidikan (kurikulum, cara mengajar, perlakuan terhadap peserta didik, evaluasi dll) dan (3) dalam pelaksanaannya diterapkan prinsip-prinsip Interaksi Simbolik. 


\section{KESIMPULAN}

Sosiologi pendidikan merupakan ilmu yang berusaha untuk mengetahui cara-cara mengendalikan proses pendidikan untuk mengembangkan kepribadian individu agar lebih baik. Sosiologi pendidikan pertamakali dikuliahkan oleh Henry Suzzalo tahun 1910 di Teacher College, Universitas Columbia. Akan tetapi, baru saja tahun 1917 terbit textbook sosiologi pendidikan yang pertama kali karya Walter R. Smith dengan judul Introduction to Educational Sociology. Pada tahun 1916, di Universitas New York dan Columbia didirikan jurusan Sosiologi Pendidikan dibentuk pada konggres himpunan sosiologi Amerika dalam tahun 1923. Sejak tahun itu diterbitkan buku tahunan sosiologi pendidikan. Pada tahun 1928, diterbitkan The Journal of Educational Sociology dibawah pimpinan E. George Payne. Majalah Social Education mulai diterbitkan tahun 1936. Sejak tahun 1940, dalam Review Education Reserch dimuat pada artikelartikel yang berhubungan dengan sosiologi pendidikan.

Adapun ruang lingkup Sosiologi Pendidikan mengacu pada penerapan pengetahuan sosiologi, teknik berfikir, dan pengumpulan data dalam penyelidikan pendidikan. Dengan demikian sosiologi pendidikan mempelajari tentang proses pendidikan sebagai interaksi sosial, sekolah sebagai kelompok sosial, serta sebagai lembaga sosial.

Model-model analisis sosiologi tentang pendidikan maliputi 4 macam analisis, (1) analisis model struktural fungsional dengan tokohnya Emile Durkeim dan Talcott Parsons, (2) analisi model konflik dengan tokohnya S. Bowles dan H. Gintis dan Louis Althuser, (3) analisis model sosiologi kritis dengan tokohnya Paulo Freire dan Ivan Illich dan (4) Analisis Pendidikan Level Mikro versi Inggris dan Amerika Serikat. 


\section{DAFTAR PUSTAKA}

Adiwikarta, Sudardja, 2016, Sosiologi Pendidikan : Analisis Sosiologi Tentang Preaktis Pendidikan, (Bandung : Remaja Rosda Karya.

Moh. Padil dan Triyo Suprayitno, 2010, Sosiologi Pendidikan, Yogyakarta: UIN-Maliki Press.

Muhammad Rifa'I, 2010, Sosiologi Pendidikan, Yogyakarta: Ar Ruzz Media.

Bambang P, Yulia B, M. Husni A, 2012, Sosiologi Pendidikan, Tangerang Selatan: Universitas Terbuka.

Nasution, 1994, Sosiologi Pendidikan, Jakarta: Bumi Akasara.

Gunawan, Ary H, 2010, Sosiologi Pendidikan : Suatu Analisis Sosiologi tentang Pelbagai Problem Pendidikan. Jakarta : Rineka Cipta.

Ahmadi, Abu, 1982, Sosiologi Pendidikan : Membahas Gejala Pendidikan Dalam Konteks Struktural Masyarakat, Surabaya : Bina Ilmu.

Idi, Abdullah, 2013, Sosiologi Pendidikan : Individu, Masyarakat, dan Pendidikan, Depok : Raja Grafindo Persada. 